\title{
Two step recovery of vision in the amblyopic eye after visual loss and enucleation of the fixing eye
}

\author{
Corina Klaeger-Manzanell, Creig S Hoyt, William V Good
}

The sensitive period for successful treatment of strabismic amblyopia is thought to be over after the age of 6 to 8 years. ' However, there are several reports that document an improvement in vision in the amblyopic eye in adulthood after loss of vision in the non-amblyopic eye. ${ }^{2-4}$ Experimental studies in adult monkeys show a significant improvement in visual function following enucleation of the fixing eye. ${ }^{5}$ In human strabismic amblyopia there are no data available about whether enucleation of the previously fixing eye after severe visual loss will further increase visual acuity. We report a case where a two step recovery of vision in an eye with strabismic amblyopia occurred.

\section{Case report}

A 44-year-old white man with strabismic amblyopia of the right eye suffered a penetrating injury to the fixing left eye which resulted in cataract extraction and aphakic retinal detachment. The amblyopia in the right eye was due to a small angle esotropia that had never been treated. His best corrected visual acuity before the accident was $6 / 60$ in the right eye and $6 / 6$ in the left eye. Fixation in the right eye was central. The refractive error was $+1.00 \mathrm{DS}+0.50 \mathrm{DC}$ $\times 90$, right eye and $+0.25 \mathrm{DS}+0.25 \mathrm{DC} \times 90$, left eye. After the retinal detachment surgery the vision in the fixing eye dropped to counting fingers at 2 metres and remained there. Six weeks after retinal detachment surgery the visual acuity of the amblyopic eye had improved spontaneously to $6 / 24$. During the following 13 months the visual acuity in the amblyopic eye remained stable at $6 / 24$ while the injured eye deteriorated to light perception only and developed constant pain and phthisis that made enucleation necessary. Three weeks after the enucleation the visual acuity of the amblyopic eye had improved to $6 / 12$ and 4 months after the enucleation to $6 / 9$. It has remained at this level for 6 years on follow up examination. The visual acuity was always measured in the same room at 6 metres with line Snellen Optotype.

Department of

Ophthalmology,

University of California,

San Francisco, USA

C Klaeger-Manzanell

C S Hoyt

W V Good

Correspondence to:

Correspondence to:

Ophthalmology, A 704,

Ophiversityology, A 704 ,

Urancisco, CA 94143, USA.

Accepted for publication

1 February 1994
There are several reports of documented improvement of vision in the amblyopic eye after severe visual loss in the fixing eye. ${ }^{2-}$ In a retrospective multicentre report Vereecken and Brabant found an improvement of vision of at least three lines in the amblyopic eye in $28.5 \%$ of patients with vision loss in the good eye. ${ }^{2}$ This improvement, however, only occurred if fixation in the amblyopic eye was central. Typically, the improvement occurred within the first weeks

\section{Comment}

after visual loss, but sometimes took up to 2 years to reach the final visual acuity. Unfortunately in this study there is no distinction made as to whether patients only lost vision in the fixing eye or whether enucleation was involved in any of these patients. In contrast, Api and coworkers described eight strabismic amblyopic adult patients with visual loss in their previously fixing eye. ${ }^{+}$The visual acuity of the amblyopic eye improved in all of these patients independent of the age when the fixing eye was lost, previous fixation pattern, previous treatment of amblyopia, and if the loss of vision in the fixing eye was total or partial. In three of the eight patients enucleation of the previously fixing eye occurred.

In our patient, an initial improvement in vision occurred in the amblyopic eye from $6 / 60$ to $6 / 24$ within 6 weeks of vision loss in the good eye. For a year the visual acuity remained stable, although the previously fixating eye dropped in visual acuity from counting fingers at 2 metres to bare light perception. The second and drastic increase in visual acuity to $6 / 9$ occurred after enucleation of the non-amblyopic eye. The time course of acuity improvement was rapid with the biggest improvement occurring within the first few weeks.

Animal studies support this observation that visual acuity improvement may occur in the adult amblyope following enucleation of the non-amblyopic eye. In cats the removal of a nondeprived eye results in an immediate and permanent 6-fold increase in cells responding to the deprived eye in the striate cortex ${ }^{67}$ The increase is much larger when the non-deprived eye is enucleated rather than simply occluded. In monkeys removal of the non-deprived eye does not improve vision in the eye with an experimentally induced form of deprivation amblyopia. ${ }^{8}$ However, in the case of experimental strabismic amblyopia enucleation in an adult monkey can lead to a marked increase in visual function in the amblyopic eye. ${ }^{5}$

The mechanism responsible for visual improvement in the adult strabismic animal following visual loss or enucleation of a nonamblyopic eye is unknown. Nevertheless, it would appear that in some adult patients with strabismic amblyopia enucleation of the nonamblyopic eye may lead to a dramatic improvement in the visual function of the amblyopic eye.

1 Scott WE, Dickey CF. Stability of visual acuity in amblyopic patients after visual acuity. Graefes Arch Ophthalmol 1988 226: 154-7.

2 Vereecken EP, Brabant P. Prognosis for vision in amblyopia after loss of the good eye. Arch Ophthalmol 1984; 102:220-4. 
3 Hamid LM, Glaser JS, Schatz NJ. Improvement of vision in the amblyopic eye following visual loss in the contralateral normal eye: a report of three cases. Binoc Vis 1991; 6: 97-100.

4 Api S, Mena JI, Vasquez AF, Perez DG, Oropeza SM, Murillo LM. Perdida del ojo fijador en adulto con ambliopia estrabica. Anal Soc Mexican De Oftamol 1982; 56: 445-52.

5 Harwerth RS, Smith EL, Duncan GC, Crawford MLJ, von Noorden GK. Effects of enucleation of the fixing eye in strabismic amblyopia in monkeys. Invest Ophthalmol Vis $\mathrm{Sc}$ 1986; $27: 246-54$
6 Smith DC. Functional restoration of vision in the cat after longterm monocular deprivation. Science 1981; 213: 1137-9.

7 Kratz KE, Spear PD, Smith DC. Post-critical period reversal of monocular deprivation on striate cortex cells in the cat. F Neurophysiol 1976; 39: 501-11.

8 Harwerth RS, Smith EL, Crawford MLJ, von Noorden GK. Effects of enucleation of the nondeprived eye on stimulus deprivation amblyopia in monkeys. Invest Ophthalmol Vis Sci 1984; $25: 10-8$.

\section{History of ophthalmology}

\section{Skiagraphs and foreign bodies}

The use of $x$ rays in locating ocular foreign bodies is taken for granted now, but in January 1897 at the meeting of the Society of Ophthalmology, Mr Mackenzie Davidson had just described a practical technique for doing so.

'Because these Rontgen rays travel in straight lines,' he explained, 'it is only necessary to take two different views in order to locate an object.' He went on to explain that relating the position on the film to the patient's orbit was the only problem. Previous skiagraphers had come up with mathematical formulas which were so complicated as to be unusable to the surgeons of the day.

Mackenzie's technique was simple but workable. Two metal knitting needles were fixed together in a cross, and brushed generously with black ink. The patient's face was then placed firmly against them. Shooting laterally, the cross on the patient's skin appeared clearly on the film. In the anteroposterior view, the lateral distance between the foreign body and the needles could be measured.

This was good news to a certain Dr Bickerton, who was treating a grouse beater injured in the line of duty, and wished to confirm that the pellet was lodged within the orbit. Having taken $x$ rays, he was reduced to repeatedly $x$ raying a skull with a similar pellet taped in various positions, in order to guess which film of the skull looked most like his patient's. As each exposure took 15-20 minutes, this must have been tedious.

$\mathrm{Mr}$ Hartridge then applauded the use of the $x$ rays, presenting the case of a stable boy who was shot in the eye by an air rifle and admitted as an emergency to the Westminster Hospital, where a busy house officer admitted him, snipped off a prolapse of the iris and prescribed cold compresses overnight. Exhaustive search among the straw - ordered by $\mathrm{Mr}$ Hartridge revealed that a pellet could be missing, and a skiagraph 4 days later confirmed its resting place. As it appeared to be within the globe, this was enucleated, explored and the skiagraph's efficiency duly confirmed. $\mathrm{Mr}$ Hartridge then passed around the pellet.

Having been quiescent until then the President spoke, commenting that it was very easy to tell whether a foreign body was within the globe or not. If intraocular, it would move position as the globe did when the patient was asked to roll his eyes a little under the $x$ ray tube, and the company agreed that this would be very useful.

Mr Power and $\mathrm{Mr}$ Treacher Collins lamented the fact that this $x$ ray method was only recently available, as they had both enucleated several eyes on the suspicion of containing shot and had been proved wrong.

Interestingly, Mr Power questioned the wisdom of removing any eye which contained gunshot by reporting the following case. A cabman was punched in the eye by another cabman, sustaining rupture of the globe. As he had already lost one eye and feared to lose his livelihood, he begged for conservative treatment. Against his better judgment, the surgeon stitched the globe and waited. To his amazement, the eye did well and the patient was able to continue his work (presumably aided by the unimpaired vision of his horse). 'If such an "angry and severe wound" can heal, can we assume that a globe containing shot will not?', Power asked.

The only dissenting voice in the discussion was Mr Holmes Spicer, who described a patient who was blinded after shooting himself through the temples in a suicide attempt. An $x$ ray revealed one bullet within the orbit. The patient was quite upset by the examination, and succumbed to meningitis on his return. But at exhaustive post mortem, no trace of the bullet was found! 'The $x$ rays had not told the truth,' comments Holmes Spicer.

Nevertheless, the mood of the meeting was optimistic, and it was agreed that $x$ rays enable the ophthalmologist to decide whether a foreign body is in the eyeball, to locate it, and to estimate its size. And (an addendum that would galvanise a modern radiation protection officer) 'with regard to the patient I showed with partial loss of hair,' commented Mackenzie Davidson, no doubt somewhat defensively, 'this only occurred because the $x$ ray tube was a little weak, and it should not happen again'.

FIONA ROMAN

Case reports on injuries of eye and orbit. Brf Ophthalmol 1897; 43 192-219.

Mackenzie Davidson J. Roentgen rays and localisation. $B M \mathcal{F}$ 1898; Jan 1: 10-2. 